\title{
Seasonal variabilities of low-latitude mesospheric winds
}

\author{
R. Rajaram ${ }^{1,2}$, S. Gurubaran ${ }^{1}$ \\ ${ }^{1}$ Equatorial Geophysical Research Laboratory, Indian Institute of Geomagnetism, Krishnapuram, Tirunelveli 627011 , India \\ ${ }^{2}$ Indian Institute of Geomagnetism, Colaba, Mumbai 400 005, India
}

Received: 19 March 1997 / Revised: 25 August 1997 / Accepted: 2 September 1997

\begin{abstract}
Observations of mesospheric winds over a period of four years with the partial reflection radar at Tirunelveli $\left(8.7^{\circ} \mathrm{N}, 77.8^{\circ} \mathrm{E}\right)$, India, are presented in this study. The emphasis is on describing seasonal variabilities in mean zonal and meridional winds in the altitude region $70-98 \mathrm{~km}$. The meridional winds exhibit overall transequatorial flow associated with differential heating in the Northern and Southern Hemispheres. At lower altitudes $(70-80 \mathrm{~km})$ the mean zonal winds reveal easterly flow during summer and westerly flow during winter, as expected from a circulation driven by solar forcing. In the higher altitude regime $(80-98 \mathrm{~km})$ and at all altitudes during equinox periods, the mean zonal flow is subjected to the semi-annual oscillation (SAO). The interannual variability detected in the occurrence of SAO over Tirunelveli has also been observed in the data sets obtained from the recent UARS satellite mission. Harmonic analysis results over a period of two years indicate the presence of long-period oscillations in the mean zonal wind at specific harmonic periods near 240, 150 and 120 days. Results presented in this study are discussed in the context of current understanding of equatorial wave propagation.
\end{abstract}

Key words Meteorological and atmospheric dynamics . General circulation - Middle atmosphere dynamics · waves and tides.

\section{Introduction}

The equatorial and low-latitude mesosphere hosts a variety of dynamical processes some of which are confined to this region where the Coriolis frequency

Correspondence to: S. Gurubaran becomes small enough to allow certain long-period wave modes. Waves of this kind are believed to contribute significantly through the complex wave-mean flow interactions to some of the observed variations in dynamical parameters, for example, the quasi-biennial (QBO) (Reed et al., 1965; Veryard and Ebdon, 1961) and the semi-annual (SAO) (Reed, 1965; Hirota, 1978) oscillations, in the middle atmospheric mean zonal wind (Andrews et al., 1987 and the references therein). Satellite measurements with the Limb Infrared Monitor of the Stratosphere (LIMS) experiment on board Nimbus-7 and the Microwave Limb Sounder (MLS) on board UARS mission, have added new dimensions to our current understanding of the long-period equatorial wave propagation in the middle atmosphere (Salby et al., 1984; Delisi and Dunkerton, 1988; Hitchmann and Leovy, 1988; Canziani et al., 1994). Ground-based radar measurements in the equatorial region have yielded useful information on some of the propagation characteristics of the long-period waves (Vincent, 1993).

Recent efforts by many workers have fully utilized the potential of ground-based radar measurements in examining the low frequency motions in the equatorial and low-latitude mesosphere and evaluating their contributions to the observed dynamical behaviour of the mesosphere and lower thermosphere region (Vincent and Lesicar, 1991; Harris and Vincent, 1993; Fritts and Isler, 1994; Palo and Avery, 1995, 1996). However there are many unresolved problems that need to be quantitatively understood, to name a few, effects of longperiod waves on the background mean flow, gravity wave - tide - planetary wave interactions and their effects, and contribution of tides and gravity waves to the momentum budget of the equatorial mesosphere. This calls for a number of radar measurements that are separated in longitude in the equatorial region. In the early 1990s observations with a meteor radar and a new generation partial reflection radar, were initiated at Christmas Island $\left(2^{\circ} \mathrm{N}, 157^{\circ} \mathrm{W}\right)$ in the Central Pacific and preliminary results were reported (Avery et al., 1990; Vincent and Lesicar, 1991). One more partial 
reflection radar became operational at Hawaii $\left(22^{\circ} \mathrm{N}\right.$, $159^{\circ} \mathrm{W}$ ) (Fritts and Isler, 1992). In the Indian zone the meteor radar operated from Trivandrum $\left(8.5^{\circ} \mathrm{N}, 77^{\circ} \mathrm{E}\right)$ have yielded useful results on the low-latitude dynamical behaviour of the atmosphere in the meteor region (80105 km) (Raghava Reddi and Ramkumar, 1995, 1997).

The partial reflection radar at Tirunelveli $\left(8.7^{\circ} \mathrm{N}\right.$, $77.8^{\circ} \mathrm{E}$ ), India, was installed by the Indian Institute of Geomagnetism, during the middle of 1992, with assistance from Dr. R. A. Vincent and his group at the University of Adelaide, Australia. Data obtained from the partial reflection radar operated at Tirunelveli were utilized in the present study. The radar system operating on $1.98 \mathrm{MHz}$ is identical to the one placed on Christmas Island by the University of Adelaide. The system details and the mode of operation are the same as described by Vincent and Lesicar (1991) and will not be repeated here. The full correlation analysis developed by Briggs (1984) has been adopted in the present work for determining neutral winds in the sampling region. The emphasis in this study is on describing mean motions in the low-latitude mesosphere-lower thermosphere region and examining their seasonal and altitude dependence. Results on long-period wave motions and their effects on background mean flow will be presented in a forthcoming paper.

\section{Observations and data analysis}

Continuous ground-based measurements of mesospheric winds commenced at Tirunelveli in November 1992. Highest number of useful data samples are collected at $86 \mathrm{~km}$ irrespective of day or night. Useful measurements at night, however, are confined to altitudes above $80 \mathrm{~km}$. One hour-averaged data sets are accumulated on a daily basis and are made available for analysis.
There are a few data gaps of two to three week duration each during 1993 and 1994 for various reasons. Since the primary objective of the present study is to bring out seasonal variabilities in winds over a time period ranging from two to four months, we believe these data gaps do not affect the gross features revealed by the analysis.

It may be noted that at altitudes above $80 \mathrm{~km}$ full 24hour coverage of wind measurements is possible while the data sets for altitudes below $80 \mathrm{~km}$ may have some of the hourly slots unfilled during night hours. Data for the entire altitude region $(70-98 \mathrm{~km})$ were subjected to the tests described here for meaningful statistics. The averaging procedure adopted for the present work yielded hourly mean values over a selected period, for example, over a season. The overall mean at each height is computed from the mean of the hourly values. The bias towards daytime values may be minimised by this averaging method. The standard error has been computed for each of the 24 hourly mean values and the overall standard error has been calculated from the square root of sum of squares of standard error for each of the hourly values, divided by the number of hourly slots, 24 when all slots are filled. The overall standard errors for each of the heights and for all seasons for both zonal and meridional winds are represented in Tables 1 and 2. The four sets of rows represent values calculated from data sets for winter, summer, and spring (MarchApril) and fall (September-October) equinoxes. As can be seen in these tables, the overall standard error is less than $0.5 \mathrm{~ms}^{-1}\left(\sim 1.3 \mathrm{~ms}^{-1}\right.$ at $99 \%$ confidence level $)$ on most of the occasions for heights above $84 \mathrm{~km}$ and at lower heights $(70-80 \mathrm{~km})$ it takes on a wider range of values from as low as $0.4 \mathrm{~ms}^{-1}$ to as high as $7.7 \mathrm{~ms}^{-1}$. Small standard errors at higher heights indicate higher acceptance rates while much larger standard errors computed for lower heights are indicators of data sparsity in the night hours.

Table 1. Overall standard error for zonal wind

\begin{tabular}{|c|c|c|c|c|c|c|c|c|c|c|c|c|c|c|c|}
\hline \multirow[t]{2}{*}{ Season } & \multicolumn{15}{|c|}{ Altitude } \\
\hline & 70 & 72 & 74 & 76 & 78 & 80 & 82 & 84 & 86 & 88 & 90 & 92 & 94 & 96 & 98 \\
\hline \multicolumn{16}{|l|}{ Winter } \\
\hline 92 & 2.4 & 2.3 & 2.6 & 2.2 & 1.8 & 1.5 & 0.6 & 0.2 & 0.2 & 0.2 & 0.2 & 0.2 & 0.3 & 0.4 & 0.4 \\
\hline 93 & 2.6 & 3.0 & 1.7 & 3.0 & 2.5 & 1.5 & 0.5 & 0.2 & 0.1 & 0.1 & 0.2 & 0.2 & 0.2 & 0.2 & 0.3 \\
\hline 94 & 3.3 & 2.8 & 3.8 & 1.8 & 2.3 & 1.2 & 0.5 & 0.2 & 0.2 & 0.2 & 0.2 & 0.2 & 0.2 & 0.2 & 0.2 \\
\hline 95 & 2.1 & 1.6 & 2.5 & 2.0 & 1.9 & 1.8 & 2.2 & 0.6 & 0.3 & 0.2 & 0.2 & 0.2 & 0.2 & 0.2 & 0.2 \\
\hline \multicolumn{16}{|c|}{ Summer } \\
\hline 93 & 3.5 & 4.4 & 5.3 & 2.5 & 2.8 & 1.8 & 0.6 & 0.5 & 0.3 & 0.3 & 0.4 & 0.4 & 0.4 & 0.5 & 0.5 \\
\hline 94 & 1.8 & 2.0 & 1.1 & 0.7 & 1.6 & 0.5 & 3.5 & 0.7 & 0.6 & 0.7 & 0.8 & 0.8 & 1.1 & 0.2 & 0.1 \\
\hline 95 & 4.0 & 2.5 & 2.8 & 3.8 & 2.7 & 2.5 & 1.5 & 0.2 & 0.2 & 0.2 & 0.2 & 0.2 & 0.2 & 0.2 & 0.2 \\
\hline 96 & 3.5 & 0.6 & 0.6 & 0.4 & 1.2 & 2.5 & 1.1 & 0.4 & 0.2 & 0.2 & 0.2 & 0.2 & 0.3 & 0.3 & 0.3 \\
\hline \multicolumn{16}{|c|}{ Spring equinox } \\
\hline 93 & 4.5 & 4.2 & 3.7 & 3.6 & 4.0 & 3.3 & 1.0 & 0.3 & 0.2 & 0.3 & 0.3 & 0.3 & 0.4 & 0.5 & 0.6 \\
\hline 94 & 3.8 & 3.2 & 4.7 & 3.5 & 3.8 & 2.1 & 0.8 & 0.3 & 0.2 & 0.2 & 0.3 & 0.3 & 0.4 & 0.4 & 0.4 \\
\hline 95 & 2.9 & 3.2 & 2.5 & 2.1 & 3.1 & 1.7 & 0.6 & 0.2 & 0.1 & 0.2 & 0.2 & 0.2 & 0.3 & 0.3 & 0.3 \\
\hline 96 & 1.7 & 1.6 & 1.4 & 1.5 & 0.9 & 1.6 & 3.1 & 0.7 & 0.3 & 0.3 & 0.3 & 0.3 & 0.3 & 0.3 & 0.4 \\
\hline \multicolumn{16}{|c|}{ Fall equinox } \\
\hline 93 & 1.6 & 2.6 & 3.7 & 1.9 & 4.0 & 3.2 & 1.0 & 0.3 & 0.2 & 0.2 & 0.2 & 0.3 & 0.3 & 0.3 & 0.4 \\
\hline 94 & 2.2 & 4.2 & 2.1 & 0.5 & 1.2 & 2.5 & 1.6 & 0.5 & 0.4 & 0.3 & 0.4 & 0.4 & 0.6 & 0.7 & 0.7 \\
\hline 95 & 3.3 & 4.9 & 2.2 & 1.9 & 6.8 & 2.0 & 1.1 & 0.2 & 0.2 & 0.2 & 0.2 & 0.2 & 0.3 & 0.3 & 0.3 \\
\hline 96 & 1.3 & 2.4 & 2.3 & 1.3 & 7.2 & 5.5 & 2.0 & 0.6 & 0.3 & 0.2 & 0.2 & 0.2 & 0.3 & 0.3 & 0.3 \\
\hline
\end{tabular}


Table 2. Overall standard error for meridional wind

\begin{tabular}{|c|c|c|c|c|c|c|c|c|c|c|c|c|c|c|c|}
\hline \multirow[t]{2}{*}{ Season } & \multicolumn{15}{|c|}{ Altitude } \\
\hline & 70 & 72 & 74 & 76 & 78 & 80 & 82 & 84 & 86 & 88 & 90 & 92 & 94 & 96 & 98 \\
\hline \multicolumn{16}{|l|}{ Winter } \\
\hline 92 & 2.1 & 2.4 & 2.4 & 2.2 & 2.1 & 1.6 & 0.6 & 0.2 & 0.2 & 0.2 & 0.2 & 0.2 & 0.3 & 0.3 & 0.4 \\
\hline 93 & 2.5 & 2.3 & 2.5 & 2.7 & 3.5 & 1.8 & 0.6 & 0.3 & 0.2 & 0.2 & 0.2 & 0.2 & 0.2 & 0.3 & 0.3 \\
\hline 94 & 2.9 & 2.8 & 2.7 & 4.0 & 2.1 & 1.3 & 0.6 & 0.2 & 0.2 & 0.2 & 0.2 & 0.2 & 0.2 & 0.2 & 0.3 \\
\hline 95 & 3.0 & 2.4 & 2.2 & 1.9 & 2.4 & 2.6 & 1.9 & 0.9 & 0.3 & 0.2 & 0.2 & 0.2 & 0.2 & 0.2 & 0.2 \\
\hline \multicolumn{16}{|c|}{ Summer } \\
\hline 93 & 4.6 & 4.5 & 4.7 & 5.1 & 2.7 & 2.3 & 0.8 & 0.6 & 0.4 & 0.4 & 0.4 & 0.4 & 0.5 & 0.5 & 0.6 \\
\hline 94 & 2.1 & 1.5 & 1.0 & 2.7 & 2.2 & 1.4 & 3.4 & 0.7 & 0.4 & 0.5 & 0.6 & 0.8 & 0.8 & 1.0 & 1.0 \\
\hline 95 & 3.9 & 2.4 & 2.8 & 2.2 & 2.2 & 2.1 & 0.9 & 0.2 & 0.1 & 0.2 & 0.2 & 0.2 & 0.2 & 0.2 & 0.3 \\
\hline 96 & 6.1 & 0.5 & 0.5 & 0.4 & 0.8 & 1.9 & 2.5 & 1.3 & 0.4 & 0.2 & 0.3 & 0.3 & 0.3 & 0.3 & 0.3 \\
\hline \multicolumn{16}{|c|}{ Spring equinox } \\
\hline 93 & 4.2 & 4.9 & 4.5 & 4.1 & 4.5 & 3.0 & 1.1 & 0.3 & 0.2 & 0.3 & 0.3 & 0.3 & 0.3 & 0.4 & 0.5 \\
\hline 94 & 6.0 & 3.3 & 2.3 & 2.5 & 3.0 & 2.6 & 1.1 & 0.3 & 0.2 & 0.2 & 0.2 & 0.3 & 0.3 & 0.3 & 0.4 \\
\hline 95 & 2.5 & 3.2 & 2.0 & 2.3 & 4.0 & 1.7 & 0.5 & 0.2 & 0.1 & 0.2 & 0.2 & 0.3 & 0.3 & 0.3 & 0.4 \\
\hline 96 & 4.3 & 1.6 & 1.6 & 0.8 & 2.3 & 1.8 & 1.2 & 0.6 & 0.3 & 0.2 & 0.2 & 0.2 & 0.3 & 0.3 & 0.3 \\
\hline \multicolumn{16}{|c|}{ Fall equinox } \\
\hline 93 & 1.5 & 2.8 & 4.4 & 2.1 & 5.1 & 2.0 & 1.1 & 0.4 & 0.3 & 0.3 & 0.3 & 0.3 & 0.4 & 0.5 & 0.5 \\
\hline 94 & 4.9 & 5.2 & 4.1 & 1.4 & 2.6 & 3.4 & 1.5 & 0.4 & 0.3 & 0.3 & 0.3 & 0.4 & 0.5 & 0.5 & 0.6 \\
\hline 95 & 3.2 & 3.9 & 2.6 & 2.3 & 7.7 & 2.6 & 1.3 & 0.3 & 0.2 & 0.2 & 0.2 & 0.3 & 0.3 & 0.4 & 0.4 \\
\hline 96 & 2.0 & 2.4 & 1.0 & 1.1 & 3.3 & 3.8 & 1.1 & 0.5 & 0.3 & 0.2 & 0.2 & 0.2 & 0.3 & 0.3 & 0.3 \\
\hline
\end{tabular}

\section{Results}

3.1 Mean motions in the low latitude mesosphere-lower thermosphere region

\subsubsection{Zonal wind}

The time-height cross-sections of 30-day averaged zonal winds from 70 to $98 \mathrm{~km}$ for the three consecutive years, 1993, 1994 and 1995 and up to August 1996, are shown in Fig. 1. Contours provided with slanted lines represent regimes of eastward flow. As can be seen in the figure, there has been westward flows observed during each of the equinoxes and eastward flows observed during solstices. The contours on many occasions clearly reveal downward trend. In particular the descent of the westward phase disappears at the lowest altitude sampled by the end of July every year. An eastward regime begins at the highest altitudes during the first week of May to be followed by a descent. The flow becomes westward during August and there is a tendency for the phase to descend. All these features are consistent with the semi-annual oscillation (SAO) in the zonal wind reported from other locations (Vincent, 1993, and references therein). It is to be noted that the westward flow during the fall equinox is much weaker when compared to the flow during the spring equinox.

An important feature revealed by the analysis is the inter-annual variability in the enhanced westward flow during spring equinox near the mesopause region. Peak westward flows of $\sim 80 \mathrm{~ms}^{-1}$ and $\sim 55 \mathrm{~ms}^{-1}$ were observed during 1993 and 1995, respectively. The flows had been relatively weaker during the equinox periods of 1994 and 1996. This feature is qualitatively identical to the one detected by Burrage et al. (1996) in data samples obtained from the UARS satellite mission. Burrage et al. (1996) interpret this variability as a manifestation of the quasi-biennial oscillation (QBO) in the mesospheric zonal wind.

Altitude profiles of time-mean zonal winds for the four seasons (equinoxes and solstices) are depicted in Fig. 2. Though there is large inter-annual variability in

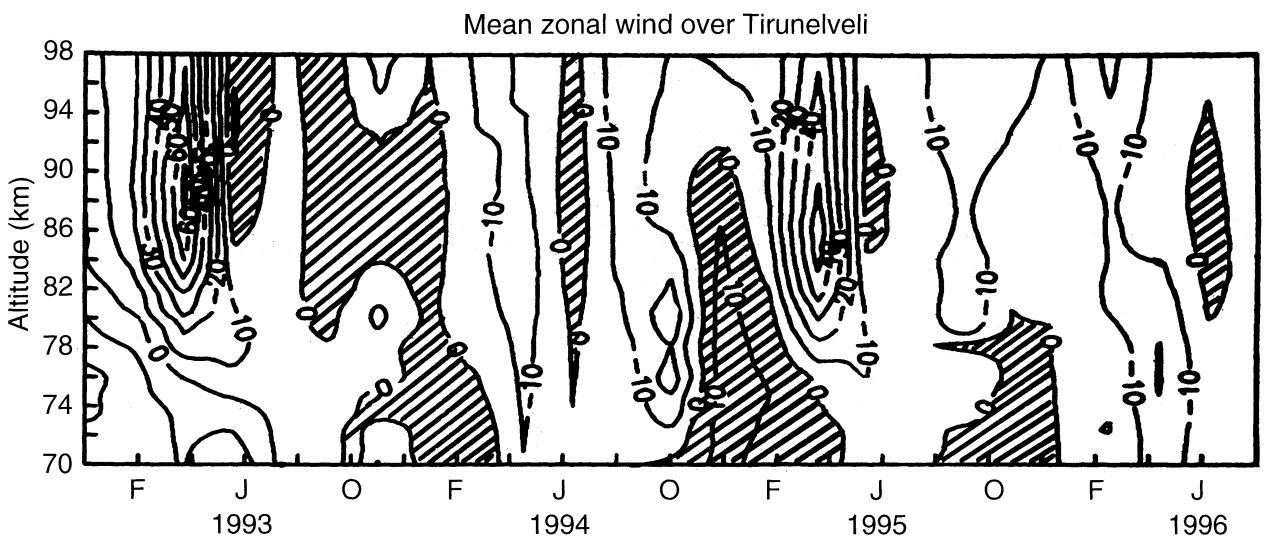

Fig 1. Mean (30-day averaged) zonal wind over Tirunelveli from December 1992 to August 1996. Contours provided with slanted lines represent regimes of eastward flow 

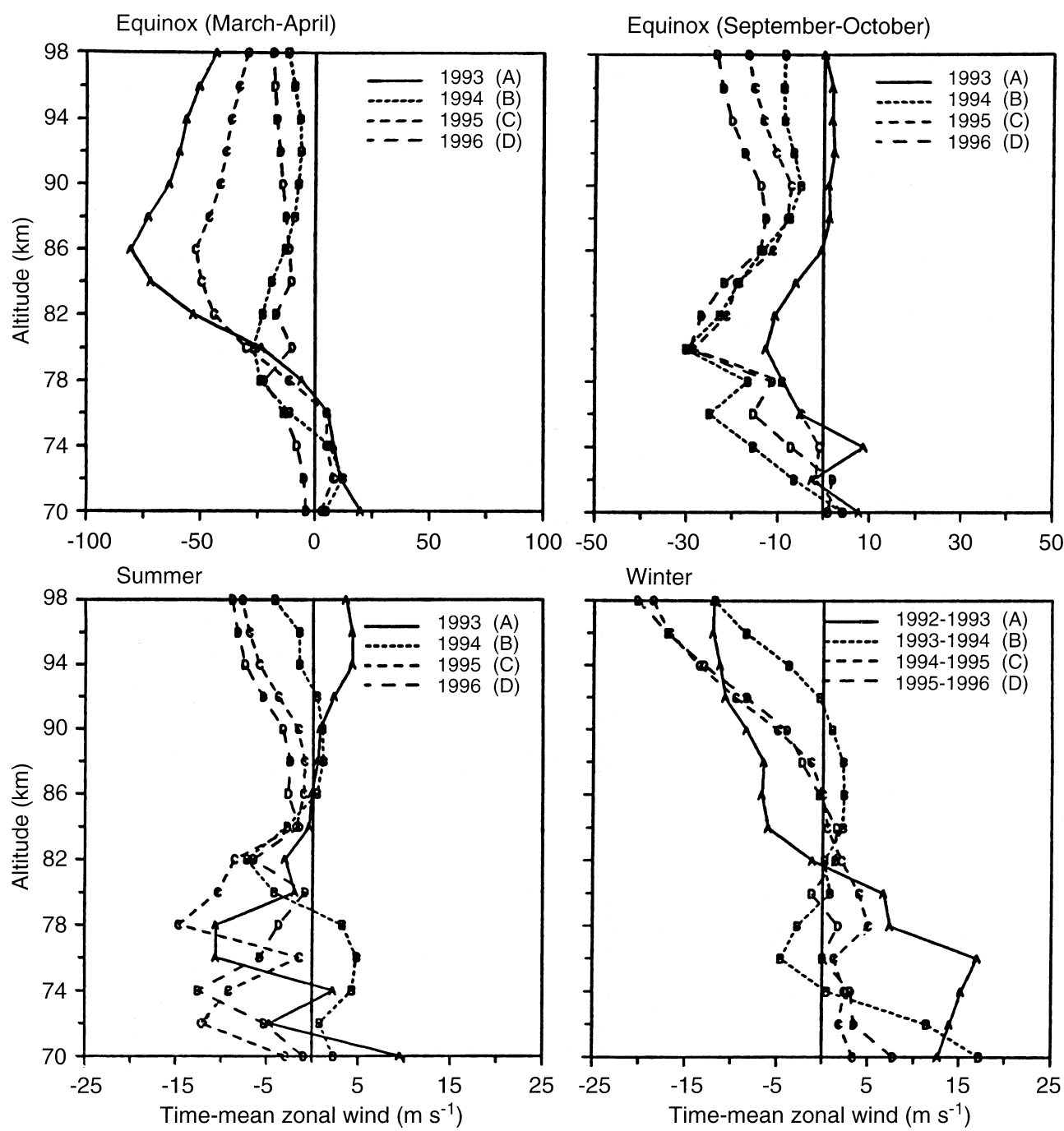

Fig 2. Altitude profiles of timemean zonal wind over Tirunelveli; (top left) March-April equinox; (top right) September-October equinox; (bottom left) summer; (bottom right) winter

the observed winds, the altitude dependence of zonal winds for each season is quite consistent. During the spring equinox period every year, the motion was eastward at heights below $76 \mathrm{~km}$ and westward above, the exception being westward flow which persisted at all heights above $70 \mathrm{~km}$ in 1996 . One may notice westward speeds as large as $75 \mathrm{~ms}^{-1}$ at $86 \mathrm{~km}$ during 1993, which were comparatively much smaller $\left(\sim 20 \mathrm{~ms}^{-1}\right)$ during 1994 and 1996. Highest speeds of $\sim 50 \mathrm{~ms}^{-1}$ were observed at $86 \mathrm{~km}$ for the year 1995. The other important feature revealed by the analysis is that during the years 1994 and 1996 when the zonal motion was slower, the westward flow attained maximum speed at lower altitudes $(78-80 \mathrm{~km})$.

The wind profiles for fall equinox period depicted in Fig. 2 all have maxima at $80 \mathrm{~km}$ similar to the curves shown for 1994 and 1996 spring equinox. Wind speeds for 1993 were systematically smaller than those for 1994 and 1995. The summer and winter curves depicted in the bottom panel of Fig. 2 reveal larger variability. During winter a clear transition in mean zonal wind was observed with eastward speeds at lower altitudes and westward speeds at higher altitudes. The winter zonal wind for 1993-1994 had undergone a brief change-over to westward direction at lower altitudes before becoming eastward again. Winter curves for 1994-1995 and 1995-1996 are identical revealing very small differences in wind magnitudes. During summer, 1995 and 1996 curves reveal time-mean westward flow at all altitudes. There has been net eastward motion during 1993 summer above $84 \mathrm{~km}$.

\subsubsection{Meridional wind}

The time-height cross sections of 30-day averaged meridional winds from 70 to $98 \mathrm{~km}$ for three consecutive years 1993, 1994 and 1995, are shown in Fig. 3. Contours enclosed by slanted lines represent regimes of poleward flow. The contours reveal transequatorial flow with poleward motion during winter and equatorward motion during summer. There has been enhanced poleward flow $\left(\sim 20 \mathrm{~ms}^{-1}\right)$ during August-September period in 1993. The mean poleward wind speeds during winter were relatively much smaller during the years 1994 and 1995 when compared to speeds during 1993.

Altitude profiles of time-mean meridional winds for the four seasons are depicted in Fig. 4. There has been a 

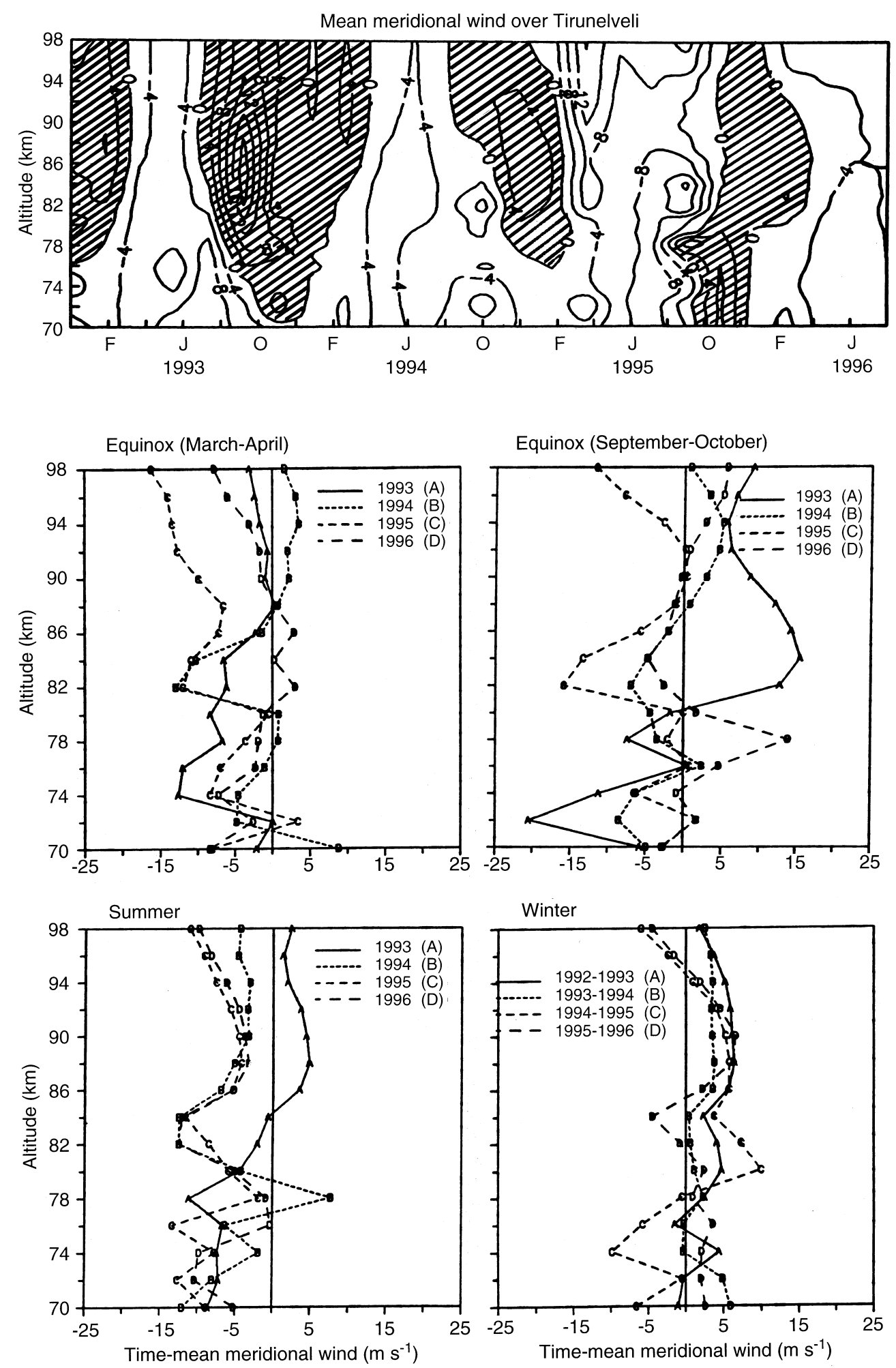

Fig 3. Same as Figure 1 but for meridional wind. Contours provided with slanted lines represent regimes of poleward flow
Fig 4. Same as Figure 2 but for meridional wind large inter-annual variability during equinoxes while solstice curves reveal transequatorial flow from the summer to winter hemisphere mentioned already. Intense poleward winds during the fall equinox of 1993 appear to be unusual. No such enhancements in poleward motion were observed in the results reported from the UARS satellite mission during this period (Burrage et al., 1996).

\subsection{Harmonic analysis results for the mean zonal wind}

For intercomparison with results reported from elsewhere, the amplitude and phase of the semi-annual oscillation in the mean zonal wind were computed by subjecting the daily mean values of the partial reflection radar data to harmonic analysis. The results, computed for the year 1995, yield a peak amplitude of about 
$25 \mathrm{~ms}^{-1}$ at $84 \mathrm{~km}$ for the semi-annual oscillation which is about $5-6 \mathrm{~ms}^{-1}$ more than that obtained for Christmas Island (Vincent, 1993) (Fig. 5). The phase remained constant above $86 \mathrm{~km}$ at values between day numbers 167 and 169. At lower altitudes the phase showed a downward descent at a rate of about $5.5 \mathrm{~km}$ per month. Both the figures agree remarkably well with those obtained for Christmas Island (165-167 and $5 \mathrm{~km}$ per month respectively). Results from Christmas Island were earlier compared with those from HRDI data on UARS satellite mission and data obtained from rocketsondes launched from Ascension Island $\left(8^{\circ} \mathrm{S}, 14^{\circ} \mathrm{W}\right)$ (Hirota, 1978; Burrage et al., 1996). Though the computed phases were identical, there were differences in SAO amplitude. The amplitudes determined by Ascension Island rockets and by HRDI both exhibited maxima at about $82 \mathrm{~km}$ with values in the range 30 to $35 \mathrm{~ms}^{-1}$, while the maximum amplitude determined by Christmas Island radar had a value of only about $18 \mathrm{~ms}^{-1}$ at about $84 \mathrm{~km}$.

In order to obtain quantitative information on the dominant motion systems of the equatorial mesosphere, the daily mean values over a period of two consecutive years, namely, 1995 and 1996, were subjected to harmonic analysis. Since the largest period associated with the observed variability is about two years, the harmonic analysis has been carried out for two consecutive years. Results for the first ten harmonics are depicted in Fig. 6.

The semi-annual oscillation, represented by the curve labelled D in Fig. 6, clearly stands out as the dominant feature in the observed zonal wind. Analysis over the two year period yields a peak of SAO $(\sim 80 \mathrm{~km})$ that is slightly lower than that obtained by analysis over one year data. This is because, on occasions when the SAO is weaker, the reduced amplitude tends to show a peak at lower heights (refer to Fig. 2). The present analysis has

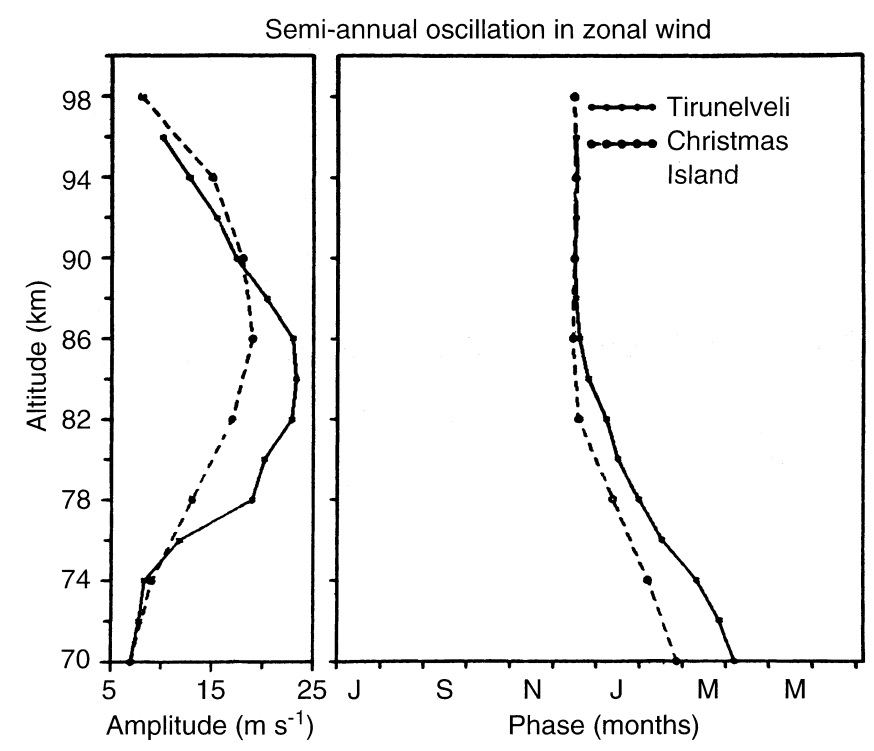

Fig 5. Amplitude and phase for the semi-annual oscillation in mean zonal wind - Comparison for Tirunelveli and Christmas Island results

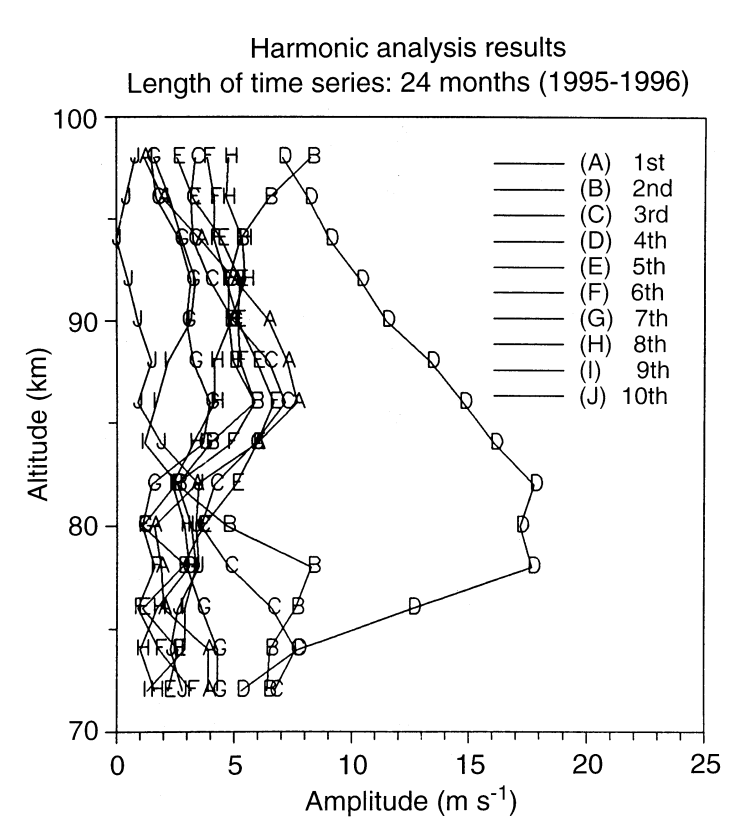

Fig 6. Harmonic analysis results for the mean zonal over a period of two years - First ten harmonics represented

been carried out over two years when the SAO had been stronger during the first year and weaker during the second year.

The first harmonic in the present analysis, represented by the curve labelled A in Fig. 6, corresponds to the period of the quasi-biennial oscillation. At heights below $82 \mathrm{~km}$ its amplitude is low $\left(3-4 \mathrm{~ms}^{-1}\right)$ while above it grows up to $\sim 8 \mathrm{~ms}^{-1}$ at $86 \mathrm{~km}$. The annual oscillation, represented by the curve labelled $\mathrm{B}$ in the figure, attains peak values at lower heights $(78 \mathrm{~km})\left(\sim 8 \mathrm{~ms}^{-1}\right)$ and tends to show an increase beyond $94 \mathrm{~km}$. The third (period of 8 months), fifth (period of 5 months) and sixth (period of 4 months) harmonics reach peaks at 86 $\mathrm{km}$ with amplitudes in the range 5-7 $\mathrm{ms}^{-1}$. The higher harmonics (with periods less than 100 days) are observed to be less significant (less than $3 \mathrm{~ms}^{-1}$ ) throughout the altitude region sampled by the radar.

\section{Discussion and conclusion}

We have presented observations of mean mesospheric winds over Tirunelveli from December 1992 to August 1996. Altitude profiles of mean meridional winds reveal features consistent with those associated with the expected transequatorial flow. The peculiar intense poleward wind observed during the equinox period of 1993 needs to be examined further. In the zonal flow there have been easterlies observed during summer and westerlies during winter over the $70-80 \mathrm{~km}$ altitude region. At midlatitudes, the mean wind pattern during solstices is driven by pole-to-pole differential solar heating and the Coriolis force acting upon the resulting meridional circulation leads to easterlies during summer and westerlies during winter in the mesosphere (Andrews et al., 1987). The observations carried out at 
Tirunelveli reveal extension of this feature to low latitudes. The transition at higher levels during winter and the tendency to remain westward during summer indicate possible momentum deposition of internal gravity waves.

The dominant feature in the observed zonal wind is the semi-annual oscillation. There appears to be an inter-annual variability in the occurrence of semi-annual oscillation in the mean zonal wind, with larger amplitudes during 1993 and 1995 and much smaller amplitudes during 1994 and 1996. This could very well be interpreted as a manifestation of the quasi-biennial oscillation in the zonal flow. Harmonic analysis results yield amplitudes in the range of $15-25 \mathrm{~ms}^{-1}$ for the SAO and $5-10 \mathrm{~ms}^{-1}$ for the QBO.

The presence of QBO in the equatorial mesosphere was confirmed earlier by Burrage et al. (1996). They had utilised data samples from the UARS satellite mission and the Christmas Island MF radar data sets. Results from the present study reveal noticeable amplitudes for the QBO thus providing support to the earlier observations.

Recently, Raghava Reddi and Ramkumar (1997) have presented results on annual and semi-annual oscillations observed in the winds obtained from the meteor wind radar at Trivandrum. They have compared their amplitude and phase profiles for the annual and semi-annual oscillations with those reported from other locations, namely, Christmas Island, Ascension Island $\left(8^{\circ} \mathrm{S}, 14^{\circ} \mathrm{W}\right)$ and $\mathrm{K} w a j a l e i n\left(9^{\circ} \mathrm{N}, 168^{\circ} \mathrm{E}\right)$. They have attributed the differences found in the profiles for the SAO to the different operational periods and possible year-to-year variability in the occurrence of SAO. Results presented in this work confirm the inter-annual variability of SAO.

Though Raghava Reddi and Ramkumar (1997) have used a limited data base during the period 1985-1987, one of the important features they have observed in the meteor wind radar data is that the AO and SAO amplitudes were significant in the meridional winds also. Their inference that the meridional wind might play an important role in the circulation associated with the AO and SAO is currently being examined with the partial reflection radar data from Tirunelveli and will be the topic for further research.

On one hand the breaking of upward propagating gravity waves has been suggested to be the causative mechanism for the SAO (Dunkerton, 1982), on the other hand it has been shown that planetary waves generate pronounced oscillations in the equatorial wind amplitudes (Delisi and Dunkerton, 1988; Garcia and Clancy, 1990). Power spectrum analysis of the partial reflection radar data on zonal and meridional winds over Tirunelveli reveals presence of long-period planetary waves near periods of 3 and 7 days which are estimated to produce eastward acceleration as large as $1 \mathrm{~ms}^{-1}$ day $^{-1}$ in the background flow. Results from this analysis will be presented in one of the forthcoming papers.

As can be seen in Fig. 2, there is a tendency for the time-mean flow to be westward at all altitudes near the mesopause region (in the altitude region $84-98 \mathrm{~km}$ ). Westward speeds when averaged over an entire year range from $4 \mathrm{~ms}^{-1}$ at $86 \mathrm{~km}$ to about $19 \mathrm{~ms}^{-1}$ at $98 \mathrm{~km}$. This exercise was carried out for the year 1995. The net westward flow has been considered to be the result of the drag imposed by the dissipating diurnal tide on the background atmospheric winds (Lindzen, 1981). Miyahara and $\mathrm{Wu}$ (1989) showed that the damping of the diurnal tide at the equator could produce steady westward winds of $10-15 \mathrm{~ms}^{-1}$. Results from UARS satellite mission revealed zonal mean circulation in the upper mesosphere and lower thermosphere (70-100 km) consisting of equatorial easterlies flanked by westerlies at mid-latitudes and cell-like patterns in the meridional winds (McLandress et al., 1996).

Finally, the presence of harmonics computed for the mean zonal wind over a period of two years at periods near 240, 150 and 120 days needs to be examined further. The selective filtering processes in the stratosphere appear to play a role in the variability of mean zonal wind at these periods.

Global observations of planetary waves, tides and gravity waves would help in an accurate determination of their effects on the observed equatorial oscillations.

Acknowledgements. We gratefully acknowledge the assistance provided by Dr. R. A. Vincent in the installation of partial reflection radar at Tirunelveli. We would like to thank D. M. Daga and K. U. Nair for their technical support and staff at Equatorial Geophysical Research Laboratory for their cooperative help in running the radar system. The constant encouragement received from Prof. B. P. Singh, Director, Indian Institute of Geomagnetism, is duly acknowledged. This work is supported by Department of Science and Technology, Government of India. We thank the reviewers for critical remarks and helpful comments on the work.

Topical Editor F. Vial thanks M. D. Burrage and L. Hirota for their help in evaluating the paper.

\section{References}

Andrews, D. G., J. R. Holton, and C. B. Leovy, Middle Atmosphere Dynamics, 489 pp, Academic Press, Orlando, FL., 1987.

Avery, S. K., J. P. Avery, T. A. Valentic, S. E. Palo, M. J. Leary, and R. L. Obert, A new meteor echo detection and collection system : Christmas Island mesospheric measurements, Radio Sci., 25, 657, 1990.

Briggs, B. H., The analysis of spaced sensor records by correlation techniques, Handb. MAP, 13, 166, 1984.

Burrage, M. D., R. A. Vincent, H. G. Mayr, W. R. Skinner, N. F. Arnold, and P. B. Hays, Long-term variability in the equatorial middle atmosphere zonal wind, J. Geophys. Res., 101, 12847, 1996.

Canziani, P. O., J. R. Holton, E. Fishbein, L. Froidevaux, and J. W. Waters, Equatorial Kelvin waves : a UARS-MLS view, J. Atmos. Sci., 51, 3053, 1994.

Delisi, D. P., and T. J. Dunkerton, Seasonal variation of the semiannual oscillation, J. Atmos. Sci., 45, 2772, 1988.

Dunkerton, T. J., Theory of the mesopause semi-annual oscillation, J. Atmos. Sci., 39, 2681, 1982.

Fritts, D. C., and J. R. Isler, First observations of mesospheric dynamics with a partial reflection radar in Hawaii $\left(22^{\circ} \mathrm{N}\right.$, 160W), Geophys. Res. Lett., 19, 409, 1992.

Fritts, D. C., and J. R. Isler, Mean motions and tidal and two-day structure and variability in the mesosphere and lower thermosphere over Hawaii, J. Atmos. Sci., 51, 2145, 1994. 
Garcia, R. R., and R. T. Clancy, Seasonal variation in equatorial mesospheric temperatures observed by SME, J. Atmos. Sci., 47, $1666,1990$.

Harris, T. J., and R. A. Vincent, The quasi-2-day wave observed in the equatorial middle atmosphere, J. Geophys. Res., 98, 10481, 1993.

Hirota, I., Equatorial waves in the upper stratosphere and mesosphere in relation to the semiannual oscillation of the zonal wind, J. Atmos. Sci., 35, 714, 1978.

Hitchman, M. H., and C. B. Leovy, Estimation of the Kelvin wave contribution to the semi-annual oscillation, J. Atmos. Sci., 45, 1462, 1988.

Lindzen, R. S., Turbulence and stress owing to gravity wave and tidal breakdown, J. Geophys. Res., 86, 9707, 1981.

McLandress, C., G. G. Shepherd, B. H. Solheim, M. D. Burrage, P. B. Hays, W. R. Skinner, Combined mesosphere/lower thermosphere winds using WINDII and HRDI data from the Upper Atmosphere Research Satellite, J. Geophys. Res., 101, 10441, 1996.

Miyahara, S., and D.-H. Wu, Effects of solar tides on the zonal mean circulation in the lower thermosphere : solstice condition, J. Atmos. Terr. Phys., 51, 635, 1989.

Palo, S. E., and S. K. Avery, Observations of the meridional quasi two-day wave in the mesosphere and lower thermosphere at Christmas Island, in The Upper Mesosphere and Lower Thermosphere : a Review of Experiment and Theory, Geophysical
Monograph Series, vol 87, Ed. by R. M. Johnson, and T. L. Killeen, pp 101-110, 1995.

Palo, S. E., and S. K. Avery, Observations of the quasi-two-day wave in the middle and lower atmosphere over Christmas Island, J. Geophys. Res., 101, 12833, 1996.

Raghava Reddi, C. and G. Ramkumar, Long-period wind oscillations in the meteor region over Trivandrum $\left(8^{\circ} \mathrm{N}, 77^{\circ} \mathrm{E}\right)$, J. Atmos. Terr. Phys., 57, 1, 1995.

Raghava Reddi, C. and G. Ramkumar, The annual and semi-annual wind fields in low latitudes, J. Atmos. Terr. Phys., 59, 487, 1997.

Reed, R. J., The quasi-biennial oscillation of the atmosphere between 30 and $50 \mathrm{~km}$ over Ascension Island, J. Atmos. Sci., 22, $331,1965$.

Reed, R. J., W. J. Campbell, L. A. Rasmussen, and D. G. Rogers, Evidence of downward propagating annual wind reversal in the equatorial stratosphere, J. Geophys. Res., 66, 813, 1965.

Salby, M. L., D. L. Hartmann, P. L. Bailey, and J. C. Gille, Evidence for equatorial Kelvin modes in Nimbus 7 LIMS, J. Atmos. Sci., 40, 220, 1984.

Veryard, R. G., and R. A. Ebdon, Fluctuations in tropical stratospheric winds, Meteorol. Mag., 90, 125, 1961.

Vincent, R. A., Long-period motions in the equatorial middle atmosphere, J. Atmos. Terr. Phys., 55, 1067, 1993.

Vincent, R. A., and D. Lesicar, Dynamics of the equatorial mesosphere : First results with a new generation partial reflection radar, Geophys. Res. Lett., 18, 825, 1991. 